\title{
Bioética para profissionais de saúde: associando exemplos práticos à reflexão teórica
}

\author{
Bioethics for health professionals: combining \\ theory and practice
}

Carlos Dimas Martins Ribeiro ${ }^{\mathrm{I}}$

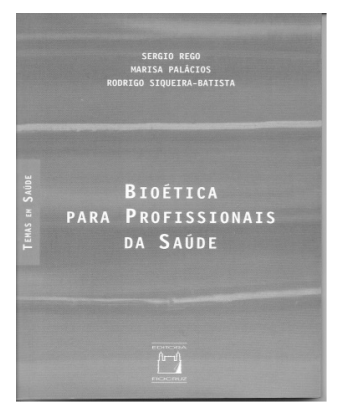

Resenha da obra de: Rego S, Palácios M, Siqueira-Batista R. Bioética para Profissionais de Saúde. Rio de Janeiro: Ed. Fiocruz; 2009. 160p. (Coleção temas em Saúde).

Os autores apresentam um panorama da bioética ao leitor não especialista, em particular ao profissional da área da saúde, que se depara, na prática cotidiana, com problemas de natureza ética. Pressupõe-se que, embora as pessoas, independentemente de sua formação, sejam capazes de tomar-e de fato tomam - decisões morais, uma formação específica na análise de problemas éticos amplia o repertório de recursos teóricos e práticos que pode ser extremamente útil nesta análise.

Os três primeiros capítulos do livro são dedicados a elementos teóricos, enquanto os dois últimos discutem aspectos práticos da bioética. Considera-se que esta não opera sem uma teoria ética, nem é a mera aplicação de teorias a casos particulares, mas, sim, uma inter-relação entre ambas, na qual tanto há maior fundamentação da análise da situação concreta, quanto um enriquecimento das teorias que se está manejando. No final do livro, apresenta-se um caminho para quem deseja se aprofundar no tema, com uma lista de sugestões de leituras e filmes. É um significativo recurso para ser utilizado em ações educativas, cineclubes e diretórios estudantis, entre outras possibilidades de ampliação do debate das questões bioéticas.

No capítulo 1 - Bioética: Histórico e Conceitos -, além de uma breve apresentação do surgimento da bioética e sua emergência no Brasil, discutem-se algumas das tensões na pesquisa científica e, em particular, na prática clínica, adotando-se um conceito de bioética que não se conforma à ética biomédica, mas se caracteriza como um campo multidisciplinar que integra saberes e conhecimentos distintos. Entre estas tensões, citam-se os questionamentos éticos relacionados aos direitos humanos individuais e coletivos, as questões relativas à escassez dos recursos e aos conflitos éticos dos profissionais de saúde quando têm que escolher qual paciente se beneficiará de determinada tecnologia e as reflexões sobre o conceito de pessoa, de vida e de morte, presentes no debate sobre o aborto e a eutanásia. Para finalizar, são feitas algumas distinções entre a bioética e outros domínios do saber-fazer - ética, moral, religião, direito, ciência e técnica -, que objetivam o reconhecimento de uma genuína questão bioética tendo em vista os diversos aspectos presentes nas situações práticas. 
O capítulo 2-A Bioética e Suas Teorias - discute as principais teorias da bioética, utilizando como exemplo o caso "A decisão do Dr. Arnaldo: quem sobe?". Nele, um médico residente de cirurgia geral de um hospital de um grande centro urbano deve decidir, entre dois pacientes baleados - um policial militar e um homem suspeito de ter alvejado o policial -, qual irá ocupar a única mesa cirúrgica disponível nas próximas quatro horas. Desta forma, são apresentadas as características principais do principialismo, do utilitarismo, da ética do cuidar e da bioética de proteção, refletindo sobre como estes modelos teóricos abordariam o caso dado como exemplo.

No capítulo 3 - Bioética e a Tomada de Decisão: entre a Clínica e a Saúde Pública -, os autores apresentam uma abordagem prática dos problemas morais na clínica, após algumas considerações relativas ao método e ao argumento em bioética. De acordo com esta abordagem, uma boa análise ética requer os seguintes elementos:

(a) informar-se adequadamente sobre a situação clínica concreta;

(b) compreender o paciente em seu contexto social;

(c) identificar as partes interessadas e as questões morais envolvidas;

(d) identificar pontos de vista, valores e interesses presentes;

(e) ponderar adequadamente riscos e benefícios;

(f) considerar as consequências financeiras das decisões;

(g) avaliar se a decisão tomada é confortável para si mesmo, podendo ser tornada pública. Em seguida, os autores discutem três aspectos das decisões na prática clínica: a tomada de decisão em nome de terceiros, sobretudo nos casos de crianças, pacientes com distúrbios mentais e pacientes que estão inconscientes; as condições do paciente no momento do atendimento, particularmente nos serviços de urgência e emergência; e os "conflitos entre os pontos de vista dos enfermos e dos profissionais de saúde", enfatizando-se o "diálogo franco e honesto com os envolvidos - enfermos, familiares, profissionais de saúde e outros -, no qual devem ser enfatizados os prós e os contras de cada decisão".

Os dois últimos capítulos versam sobre o domínio prático da bioética. O capítulo 4 - a Bioética e o Início e o Fim da Vida: o Aborto e a Eutanásia - discute o Princípio da Sacralidade da Vida (PSV) e o Princípio de Respeito à Autonomia (PRA), dois princípios morais centrais nas discussões acerca destes temas. $\mathrm{O}$ capítulo 5 - Comitês e Comissões Hospitalares de Ética e de Bioética - enfoca as especificidades e regulamentação de três organizações institucionais dedicadas à ética: as Comissões de Ética Hospitalar, os Comitês de Ética em Pesquisa e as Comissões de Bioética Hospitalar.

Duas premissas atravessam todo o livro, dando-lhe certa originalidade no campo da bioética, considerando os objetivos dos autores de oferecer um panorama da bioética aos profissionais de saúde, que, embora não sejam nem queiram ser bioeticistas, se sentem desconfortáveis com os problemas éticos da prática cotidiana e almejam manejá-los ou solucioná-los da maneira mais adequada possível. A primeira premissa é a utilização de casos, seja ilustrando um problema ético - recorrendo-se a casos que se tornaram famosos desde o surgimento da bioética -, seja discutindo estes casos à luz de determinadas teorias éticas, como no exemplo do Dr. Arnaldo. Supõe-se que um processo de aprendizagem em que se opera um vaivém entre a teoria e a situação prática facilite a apreensão das referências teóricas da bioética e o modo de aplicá-las.

A segunda premissa é que a bioética pode ser compreendida e utilizada como uma ponte entre o individual e o coletivo ou entre a clínica e a saúde pública. De fato, embora a medicina moderna tenha nascido social, inserindo o adoecimento individual numa dimensão coletiva, como nos ensinam os estudos de Michel Foucault, processou-se uma dicotomia entre a clínica e a saúde pública, separando os profissionais da saúde coletiva dos "profissionais ligados à clínica que insistem em discutir o adoecimento como um fenômeno estritamente individual". Por um lado, a promoção do bem do paciente precisa ser considerada na perspectiva do próprio, mas inserindo a relação profissional da saúde/paciente na dimensão da saúde pública e "não na noção preconcebida de que é um dever moral do profissional tomar as decisões em nome de seus pacientes", acatando sempre o que o paciente demanda em nome de um suposto respeito à autonomia do indivíduo. Por outro lado, em países como o Brasil, caracterizado por forte desigualdade e onde a maioria da população não tem seus direitos básicos garantidos, "a preocupação com a justiça e a proteção dos concidadãos" deve se tornar um verdadeiro imperativo ético.

Trata-se de um livro que deve ser lido não só por profissionais que atuam na área da saúde, - incluindo não apenas as profissões mais tradicionais, como medicina e enfermagem -, mas também por aqueles dedicados à psicologia, à fisioterapia e ao direito, entre outras, como também, e talvez especialmente, por aqueles que ainda estão se formando. De leitura fácil, mas não menos densa, esta obra constitui uma boa fonte de informações e um estímulo à reflexão, proporcionando aos leitores a possibilidade de participar de forma mais fundamentada nos debates das questões éticas no campo da saúde e da vida.

\section{ENDEREÇO PARA CORRESPONDÊNCIA}

Instituto de Saúde da Comunidade - UFF

Rua Marques do Paraná; 303, 2A do anexo do Hospital Antônio Pedro

Centro - Niteroi

Cep.: 24033-900 - RJ 